\title{
Antifungal activity of aqueous and organic extracts from Withania somnifera L. against Fusarium oxysporum f. sp. radicis-lycopersici
}

Ahlem Nefzi ${ }^{12^{*}}$, Rania Aydi Ben Abdallah ${ }^{2}$, Hayfa Jabnoun-Khiareddine ${ }^{2}$, Sined Medimagh-Saïdana ${ }^{3}$, Rabiaa Haouala ${ }^{4}$, Mejda Daami-Remadi $^{2}$

${ }^{1}$ Department of Biology, Faculty of Sciences of Bizerte, University of Carthage, Tunisia

${ }^{2}$ UR13AGR09-Integrated Horticultural Production in the Tunisian Centre-East, Regional Center of Research on Horticulture and Organic Agriculture, University of Sousse, 4042, Chott-Mariem, Tunisia

${ }^{3}$ LR11SE39-Laboratory of Heterocyclic Chemistry, Natural Products and Reactivity, University of Monastir, Tunisia

${ }^{4}$ UR13AGR05-Agrobiodiversity, The Higher Agronomic Institute of Chott-Mariem, University of Sousse, 4042, Chott-Mariem, Tunisia

\begin{abstract}
The aim of this study was to evaluate the in vitro antifungal activity of aqueous and organic extracts from native Withania somnifera L. leaves, stems, and fruits against Fusarium oxysporum f. sp. radicis-lycopersici (FORL), the causal agent of Fusarium Crown and Root Rot disease in tomato. Aqueous and organic extracts (used at 1, 2, 3 and $4 \%$ ) were added to molten Potato Dextrose Agar (PDA) medium. After pathogen challenge, cultures were incubated at $25^{\circ} \mathrm{C}$ for 5 days. All extracts tested, whatever the concentrations used, showed a strong antifungal activity toward targeted pathogen. FORL response to the different extracts assessed using the poisoned food technique, varied depending on plant organs, concentrations tested and organic solvent used for extraction. For aqueous extracts, fruit extract used at $2 \%$ exhibited the highest antifungal potential where FORL growth was decreased by $56.27 \%$, relative to the untreated control, compared to 52 and $45.34 \%$ achieved using stem and leaf extracts at $3 \%$, respectively. The highest antifungal activity of organic extracts was registred at the highest concentration used (4\%). FORL was found to be more sensitive to fruit extracts than those from leaves and stems. Among the three organic extracts tested, butanolic fractions were the most active against FORL growth. The highest antifungal potential expressed by $62.03 \%$ decrease in pathogen radial growth was displayed by butanolic stem extracts applied at $4 \%$. These results indicate that native $W$. somnifera plants may be exploited as potential source of allelochemicals biologically active against FORL.
\end{abstract}

Keywords: Antifungal activity; Extract; Fusarium oxysporum f. sp radicis- lycopersici; Mycelial growth; Withania somnifera

\section{Introduction}

Tomato (Solanum lycopersicum L.) is an important vegetable crop worldwide and ranked second after potato [1]. In Tunisia, serious economically important losses were attributed to Fusarium Crown and Root Rot (FCRR) disease incited by the soilborne fungus Fusarium oxysporum f. sp. radicis-lycopersici (FORL) Jarvis \& Shoemaker. Main disease signs are plant wilting at fruit ripening stage, cortical rot at the soil level, vascular discoloration of the lower stem and production of conspicuous pinknish masses of conidia along the stem [2]. Losses from FCRR in greenhouse tomato crops have been estimated at up to $90 \%$ [3]. Several control measures have been attempted for FCRR management, both for greenhouse and open field crops, which are restricted to soil physical and chemical desinfection and use of pathogen-free transplants. However, complete suppression of FORL from soil is difficult due to the long survival of its resting structures i.e. chlamydospores. Moreover, the most commonly used chemical fungicides, such benomyl or captafol, are not easily biodegradable and persist for years in soil which lead to environment pollution and the development of resistant strains [4]. Thus, research efforts were more focused on biological control. In fact, under Tunisian conditions, some biofungicides based on Trichoderma harzianum, Pythium oligandrum, Bacillus subtilis, B. pumilus have decreased FORL mycelial growth by 50 to $73 \%$. T. harzianun strain T22 has also reduced disease incidence to 5.5\% under greenhouse conditions [5]. In addition, Hibar et al. [3] and Kerkeni et al. [6,7] also showed the FCRR-suppressive effects of some compost extracts and their associated microorganisms.

In modern agriculture, attention was increasingly focused on the development of effective alternatives of natural origin for plant bioagressors' management. Interestingly, wild and cultivated plants are a potential source of biotic and abiotic antifungal agents [8] which are ecofriendly and may act as safe bio-based fongicides. Several previous studies have been focused on use of aqueous and organic extracts from various plant speciess for the control of some phytopathogenic fungi $[9,10]$. In this regard, few investigations were performed to screen the antifungal properties of some botanical extracts against FORL $[11,12]$.

Antifungal potential of plant-derived allelochemicals has been demonstrated in various previous studies [13-15]. In fact, aqueous and organic extracts from different Trigonella foenum-graecum organs were screened for their ability to suppress growth of five phytopathogenic fungi (namely Botrytis cinerea, F. graminearum, Pythium aphanidermatum, Alternaria sp., and Rhizoctonia solani) where the most active antifungal compounds were detected in methanol fraction from fenugreek leaves and stems [16]. Acetone extracts from Cestrum laevigatum, Nicotiana glauca, Solanum mauritianum, Lantana camara, Datura stramonium, Ricinus communis, and Campuloclinium macroephalum were also screened for their ability to suppress ten phytopathogenic

*Corresponding author: Ahlem Nefzi, UR13AGR09-Integrated Horticultural Production in the Tunisian Centre-East, Regional Center of Research on Horticulture and Organic Agriculture, University of Sousse, 4042, Chott-Mariem Tunisia, Tel: 73226 611; E-mail: nefzi_ahlem@yahoo.fr

Received February 18, 2016; Accepted March 10, 2016; Published March 18, 2016

Citation: Nefzi A, Aydi Ben Abdallah R, Jabnoun-Khiareddine H, MedimaghSaïdana S, Haouala R, et al. (2016) Antifungal activity of aqueous and organic extracts from Withania somnifera L. against Fusarium oxysporum f. sp. radicis-lycopersici. J Microb Biochem Technol 8: 144-150. doi: 10.4172/19485948.1000277

Copyright: () 2016 Nefzi A, et al. This is an open-access article distributed under the terms of the Creative Commons Attribution License, which permits unrestricted use, distribution, and reproduction in any medium, provided the original author and source are credited. 
Citation: Nefzi A, Aydi Ben Abdallah R, Jabnoun-Khiareddine H, Medimagh-Saïdana S, Haouala R, et al. (2016) Antifungal activity of aqueous and organic extracts from Withania somnifera L. against Fusarium oxysporum f. sp. radicis-lycopersici. J Microb Biochem Technol 8: 144-150. doi: 10.4172/1948-5948.1000277

fungi including F. oxysporum [17]. Al-Rahmah et al. [18] reported that methanolic extracts from Thymus vulgaris and Zingiber officinales were strongly active against F. oxysporum, P. aphanidermatum and R. solani infecting tomato. On the other hand, some Solanaceae species showed a conserved position of genes conferring resistance to some plant pathogens. Thus, Cillo et al. [19] reported that wild tomato species (Solanum section Lycopersicon), have been often employed by breeders as sources for intergressing disease resistance for tomato genetic breeding. Similar antimicrobial activity of wild Solanaceae species has been reported in various studies [20-24].

Withania somnifera (Ashwagandha) is a wild Solanaceae plant. It is one of the extremely interesting medicinal plants with pharmaceutical applications. Ashwagandha is a valuable drug associated with various therapeutic properties. Recent studies have assessed the anti-stress, anti-inflammatory, anti-tumour, antibiotic, and anticonvulsant activities in this plant. These activities are more attributed to withaferin A and withanone, the two major steroids found in its leaves and roots [8]. Several studies were focused on the efficient antifungal activity of Ashwagandha extracts against clinical fungi. For instance, Sailaja [25] demonstrated the potent antifungal activity of methanolic stem extracts from W. somnifera against Alternaria alternata, Curvularia lunata, and Candida albicans. In another study, $W$. somnifera was found to be very effective against human Apergillus infections [26]. Mahesh and Satish [27] demonstrated that methanol root, leaf and bark extracts from $W$. somnifera showed a significant antibacterial activity against Bacillus subtilis, Escherichia coli, Pseudomonas fluorescens, Staphylococcus aureus, and Xanthomonas axonopodis pv. malvacearum and C. albicans [28]. However, few reports were focused on its antifungal activity against plant pathogenic fungi. In fact, Girich et al. [8] have demonstrated that W. somnifera root aqueous extract contains a glycoprotein (WSG) with fungistatic effect toward three phytopathogenic fungi namely Aspergillus flavus, F. oxysporum, and F. verticilloides by inhibiting their spore germination and hyphal growth. Baka [29] showed that aqueous extracts from $W$. somnifera leaves were able to inhibit the mycelial growth and spore germination of some phytopathogenic fungi such Alternaria brassicae, A. solani, Botrytis fabae, F. oxysporum, and Phytophthora infestans.

In this paper, we investigate the in vitro antifungal activity of leaf, stem and fruit aqueous and organic extracts from wild $W$. somnifera plants collected from Tunisia against FORL.

\section{Materials and Methods}

\section{Plant material}

Fresh and healthy W. somnifera leaves, stems, and fruits (Figure 1) were collected from Tunisian littoral, Chott-Mariem (latitude $35^{\circ} 56^{\prime} 20.451$ "N, longitude E10³3'32.028") in November 2013. Fresh materials were washed thoroughly under running tap water to remove any dust, and were dried at room temperature at $30^{\circ} \mathrm{C}$ for $72 \mathrm{~h}$ and grounded into fine powder before being used for extraction.

\section{Fungal agent}

FORL isolate used in this study was originally recovered from tomato plants showing typical symptoms of Fusarium Crown and Root Rot (FCRR) disease. Fungal cultures were grown on Potato Dextrose Agar (PDA) medium and incubated at $25^{\circ} \mathrm{C}$ for 5 days before being used for antifungal bioassays.

\section{Preparation of aqueous and organic extracts}

Aqueous extracts were prepared by soaking $30 \mathrm{~g}$ of dried leaf, stem and fruit powder from $W$. somnifera in $100 \mathrm{ml}$ of sterilized distilled water (SDW) for $24 \mathrm{~h}$. Extracts were filtered through a double layered muslin cloth followed by Whatman No. 1 filter paper and then passed through $0.22 \mu \mathrm{m}$ micro-filter pore size to remove bacteria. Filtrates were stored at $4^{\circ} \mathrm{C}$ and were generally used within a week to avoid any prospective chemical alterations [30].

For organic extract's preparation, an amount of $100 \mathrm{~g}$ of the powdered samples (W. somnifera leaves, stems and fruits) was extracted by maceration with $\mathrm{MeOH}-\mathrm{H}_{2} \mathrm{O}(7: 3)(\mathrm{v} / \mathrm{v})$ for $72 \mathrm{~h}$ at room temperature. The hydro-methanolic extraction was carried out in triplicate. After filtration, the solvent was removed with Rotavapor under reduced pressure at $45-50^{\circ} \mathrm{C}$ [31]. Aqueous layer was further subjected to successive extractions using organic solvents of increasing polarity namely Chloroform $(\mathrm{CHCl})$, ethyl acetate (EtOAc), and butanol $(\mathrm{n}-\mathrm{BuOH}) . \mathrm{CHCl}, \mathrm{EtOAc}$ and $\mathrm{n}-\mathrm{BuOH}$ extracts were evaporated to dryness under reduced pressure at $30-40^{\circ} \mathrm{C}, 40-55^{\circ} \mathrm{C}$, and $70-80^{\circ} \mathrm{C}$, respectively. A sample of each dry residue $(1 \mathrm{mg})$ obtained was individually dissolved in $1 \mathrm{ml}$ of Dimethyl sulfoxide (DMSO). The stock extract was stored at $4^{\circ} \mathrm{C}$ and used within 4 days.

\section{Determination of extraction yield}

The yield $(\%, w / w)$ from all the dried extracts was calculated as:

$$
\text { Yield }(\%)=(W 1 / W 2) \times 100
$$

where $\mathrm{W} 1$ is the weight of the extract after evaporation of solvent, and $\mathrm{W} 2$ is the weight of the plant powder.

\section{Antifungal activity assay}

The poisoned food technique [32] was used for the screening of the antifungal activity of extracts tested against FORL. Appropriate quantities of aqueous extracts from $W$. somnifera leaves, stems and fruits were added to molten PDA medium cooled to 45 to $50^{\circ} \mathrm{C}$, at 1 , 2,3 and $4 \%(\mathrm{v} / \mathrm{v})$ concentrations before being poured in sterilized Petri dishes ( $9 \mathrm{~cm}$ in diameter). The extracts were thoroughly mixed with the medium. DMSO and SDW were used as negative control while carbendazim-based fungicide (Bavistin ${ }^{\bullet} \mathrm{DF}$ ) was used as positive control. After medium solidification, three agar plugs $(6 \mathrm{~mm}$ in

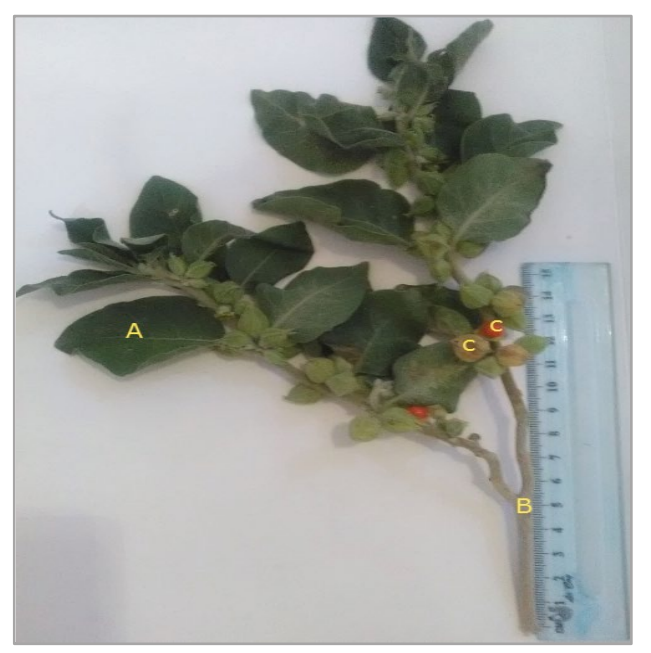

Figure 1: Withania somnifera leaves (A), stem (B) and fruits (C). 
Citation: Nefzi A, Aydi Ben Abdallah R, Jabnoun-Khiareddine H, Medimagh-Saïdana S, Haouala R, et al. (2016) Antifungal activity of aqueous and organic extracts from Withania somnifera L. against Fusarium oxysporum f. sp. radicis-lycopersici. J Microb Biochem Technol 8: 144-150. doi: $10.4172 / 1948-5948.1000277$

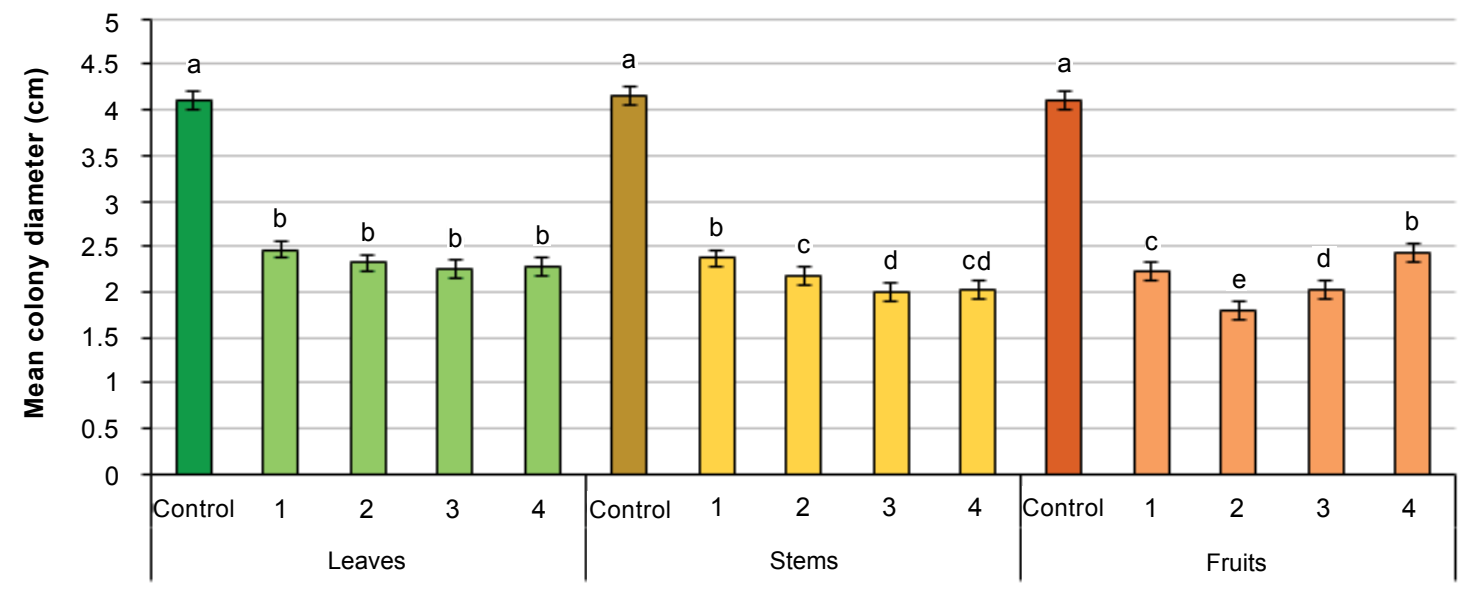

Aqueous extracts tested at four concentrations (\% v/v)

Figure 2: Mean colony diameter (cm) of Fusarium oxysporum f. sp. radicis-lycopersici grown on PDA medium supplemented with different concentrations of aqueous extracts from Withania somnifera leaves, stems and fruits noted after 5 days of incubation at $25^{\circ} \mathrm{C}$.

Control: Negative control (untreated control) i.e. PDA+SDW. Bars show standard error. For extracts from each organ used, bars sharing the same letter are not significantly different according to Student-Newman-Keuls (SNK) test (at $P \leq 0.05)$. LSD (Organs $\times$ Concentrations tested $=0.60 \mathrm{~cm}$ at $P \leq 0.05$ ).

diameter) were removed using a pre-sterilized cork borer from 5-dayold FORL cultures and placed equidistantly in each Petri plate.

W. somnifera organic extracts were also assessed for their ability to suppress in vitro growth of FORL using the same method as for aqueous extracts. Dry residues from each solvent were dissolved in DMSO at the rate of $1 \mathrm{mg}$ per $1 \mathrm{ml}$ of DMSO. They were added to molten PDA at 1,2, 3 and $4 \%(\mathrm{v} / \mathrm{v})$ concentrations. Control PDA plates were treated using DMSO only. As done for aqueous extracts' screening, three agar plugs were placed equidistantly in each Petri plate after medium solidification.

Mean FORL colony diameter $(\mathrm{cm})$ was recorded after 5 days of incubation at $25^{\circ} \mathrm{C}$. Fungal growth was measured by averaging the two perpendicular diameters of each growing colony. Percentage growth inhibition (\%) of FORL was calculated according to the following formula: Growth inhibition Growth inhibition $(\%)=[(d c-d t) / d c] \times 100$

Where $\mathrm{dc}=$ Colony diameter in control plates; $\mathrm{dt}=$ Colony diameter in treated plates.

\section{Statistical analysis}

Data were subjected to one-way analysis of variance (ANOVA) using SPSS 20.0 for Windows. Aqueous extracts trial was performed according to a completely randomized factorial design where $W$. somnifera organs targeted for extraction and tested concentrations represented the both fixed factors. Organic extracts trial was carried out according to a completely randomized factorial model with three factors (plant organs, type of organic extract used, and concentrations tested). Each individual treatment was replicated thrice. The whole experiment was repeated twice. Means were separated using LSD or Student-Newman-Keuls (SNK) test (at $P \leq 0.05$ ).

\section{Results}

\section{Antifungal activity of Withania somnifera aqueous extracts}

Analysis of variance revealed that FORL colony diameter varied significantly (at $P \leq 0.01$ ) depending on $W$. somnifera aqueous extracts used and concentrations tested; a significant interaction was detected between both fixed factors. In fact, all extracts tested were shown to be effective in suppressing FORL in vitro growth but with a varied degree depending on extracts' origin and concentrations used. Data given in Figure 2 showed that for leaf aqueous extract, the four concentrations used let to a significantly similar antifungal effect where FORL mycelial growth decrease was of about $42.5 \%$ relative to the untreated control. However, stem aqueous extract was found to be more active at 3 and $4 \%$ by inducing a respective reduction of pathogen growth by 52 and $51.6 \%$ compared to 43.20 and $47.60 \%$ achieved using this extract at 1 and $2 \%$, respectively. For fruit aqueous extract, the greatest inhibition was registred at $2 \%$ concentration leading to $56.27 \%$ decrease in FORL growth as compared to the untreated control while with the other concentrations, growth inhibition ranged between 40.89 and $50.6 \%$ (Figure 4).

It should be highlighted that carbendazim-based fungicide (Bavistin - DF, positive control) had totally (100\%) suppressed pathogen growth but SDW-based treatment (negative control) did not inhibit FORL growth. All $W$. somnifera aqueous extracts tested were found to be active toward FORL with fruit aqueous extract applied at $2 \%$ being the most effective leading to $56.27 \%$ decrease in pathogen radial growth.

\section{Antifungal activity of Withania somnifera organic extracts}

Yields of extracts: One hundred grams of powdered W. somnifera leaves, stems, and fruits, individually subjected to $\mathrm{MeOH}-\mathrm{H}_{2} \mathrm{O}$ extraction (7:3) followed by successive extractions using $\mathrm{CHCl}$, EtOAc, and $\mathrm{n}-\mathrm{BuOH}$ yielded variable dry residues depending on organs used. In fact, leaf extracts' yields were of about $0.99,0.84$, and $1.38 \%$ for chloroform, ethyl acetate and butanol fractions, respectively, compared to $0.95,0.93$, and $1.23 \%$ yielded from stems and to $0.91,1.18$, and $1.53 \%$ obtained from fruits' fractions (Table 1).

\section{Antifungal activity}

ANOVA analysis revealed that FORL colony diameter, noted after 5 days of incubation at $25^{\circ} \mathrm{C}$, varied significantly depending on organs used for extraction, organic extracts tested and concentrations used. A significant interaction (at $P \leq 0.01$ ) between the three fixed factors was also detected. 
Citation: Nefzi A, Aydi Ben Abdallah R, Jabnoun-Khiareddine H, Medimagh-Saïdana S, Haouala R, et al. (2016) Antifungal activity of aqueous and organic extracts from Withania somnifera L. against Fusarium oxysporum f. sp. radicis-lycopersici. J Microb Biochem Technol 8: 144-150. doi: $10.4172 / 1948-5948.1000277$
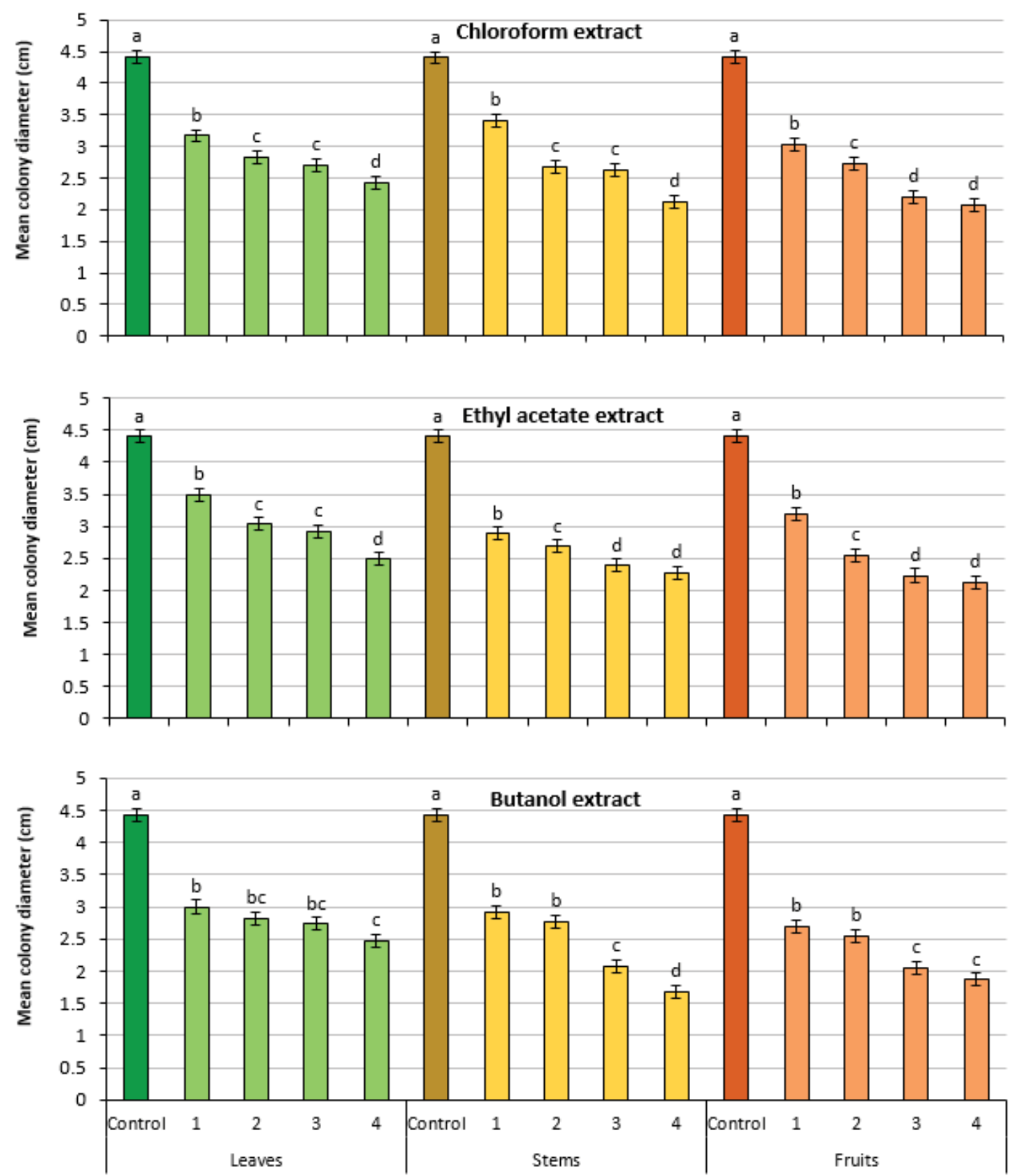

Organic extracts tested at four concentrations $(\% \mathrm{v} / \mathrm{v})$

Figure 3: Mean colony diameter of Fusarium oxysporum f. sp. radicis-lycopersici colonies grown on PDA medium supplemented with different concentrations of Withania somnifera leaf, stem and fruit organic extracts noted after 5 days of incubation at $25^{\circ} \mathrm{C}$.

Negative Control: PDA + DMSO (untreated control). Bars show standard error. For extract type from each organ used, bars sharing affected by the same letter are not significantly different according to Student-Newman-Keuls (SNK) test (at $P \leq 0.05)$. LSD (Organs $\times$ Type of extracts $\times$ Concentrations tested $=0.41 \mathrm{~cm}$ at $P \leq 0.05$ ).

Data given in Figure 3 showed that all organic extracts tested exhibited antifungal activity and had inhibited pathogen radial growth, as compared to the untreated control, in a concentration-dependant manner. In fact, pathogen inhibition reached $45.28,51.89$, and $53.21 \%$ using $W$. somnifera chloroform extracts from leaves, stems, and fruits used at $4 \%$, respectively, compared to $28.30,22.34$, and $31.32 \%$ achieved using these extracts at $1 \%$ (Figure 3 ).
For ethyl acetate fractions, FORL radial growth was 43.56, 48.48, and $51.70 \%$ lesser than the untreated control when grown on PDA supplemented at $4 \%$ with leaf, stem and fruit ethyl acetate fractions in contrast to $20.45,34.47$, and $27.55 \%$ noted when these extracts were tested at $1 \%$ (Figure 3 ).

Butanolic extracts from W. somnifera leaves, stems and fruits, used at $4 \%$, had also suppressed pathogen growth by $44.15,62.03$, 
Citation: Nefzi A, Aydi Ben Abdallah R, Jabnoun-Khiareddine H, Medimagh-Saïdana S, Haouala R, et al. (2016) Antifungal activity of aqueous and organic extracts from Withania somnifera L. against Fusarium oxysporum f. sp. radicis-lycopersici. J Microb Biochem Technol 8: 144-150. doi: 10.4172/1948-5948.1000277

\begin{tabular}{|c|c|c|c|c|}
\hline & Start material (g) & \multicolumn{3}{|c|}{ Yield (\%) } \\
\hline Samples & & Chloroform & Ethyl acetate & Butanol \\
\hline Leaf powder & 100 & 0.99 & 0.84 & 1.38 \\
\hline Stem powder & 100 & 0.95 & 0.93 & 1.23 \\
\hline Fruit powder & 100 & 0.91 & 1.18 & 1.53 \\
\hline
\end{tabular}

Table 1: The percentage yields of organic extracts prepared from Withania somnifera leaves, stems and fruits.

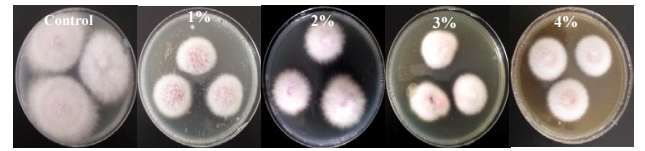

Figure 4: Fusarium oxysporum f. sp. radicis-lycopersici (FORL) colonies grown on PDA medium supplemented with aqueous extracts from Withania somnifera fruits, tested at four concentrations $(1,2,3$, and $4 \% \mathrm{v} / \mathrm{v})$ recorded after 5 days of incubation at $25^{\circ} \mathrm{C}$.

Negative Control: Untreated control (PDA + distilled water). The highest inhibition (56.28\%) of FORL mycelial growth was recorded at the concentration $2 \%$ as compared to the untreated control.

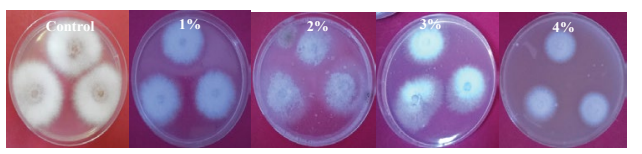

Figure 5: Fusarium oxysporum f. sp. radicis-lycopersici (FORL) colonies grown on PDA medium supplemented with butanolic extract from Withania somnifera fruits tested at four concentrations $(1,2,3$, and $4 \% \mathrm{v} / \mathrm{v})$ recorded after 5 days of incubation at $25^{\circ} \mathrm{C}$.

Negative Control: Untreated control (PDA + DMSO). The highest inhibition $(57.78 \%)$ of FORL mycelial growth was recorded at the concentration $4 \%$ as compared to the untreated control.

and $57.74 \%$, relative to control, respectively, whereas their antifungal potential decreased to $32.08,34.21$, and $38.87 \%$ when applied at $1 \%$ (Figures 3 and 5).

The present screening showed that $W$. somnifera fruit extracts were more active against FORL than those from leaves and stems. Similarly, butanolic extract was found to be relatively more effective in suppressing FORL growth than chloroform and ethyl acetate extracts which showed similar effect. In addition, for concentrations used, it was shown that highest mycelial growth inhibition of the targeted pathogen was mainly reached at the highest concentration applied (4\%) (Figures 3 and 6).

It should be highlighted that carbendazim-based fungicide (Bavistin - DF, positive control) had totally (100\%) suppressed pathogen growth but DMSO-based treatment (negative control) did not inhibit FORL growth.

\section{Discussion}

The search of new fungicides effective, biodegradable and with greater selectivity is necessary to face chemicals' related problems. Natural plant-derived products are safe and could be integrated into pest managment programs as they display antifungal activity without being phytotoxic [33]. In this study, aqueous, chloroform, ethyl acetate, and butanol extracts from $W$. somnifera leaves, stems and fruits, were screened in vitro at four concentrations $(1,2,3$, and $4 \%)$ for their ability to suppress FORL growth.

The use of solvents with varying polarity in the extraction procedure is determinal for the successful isolation of compounds with different ranges of polarity. Results showed that butanol extraction
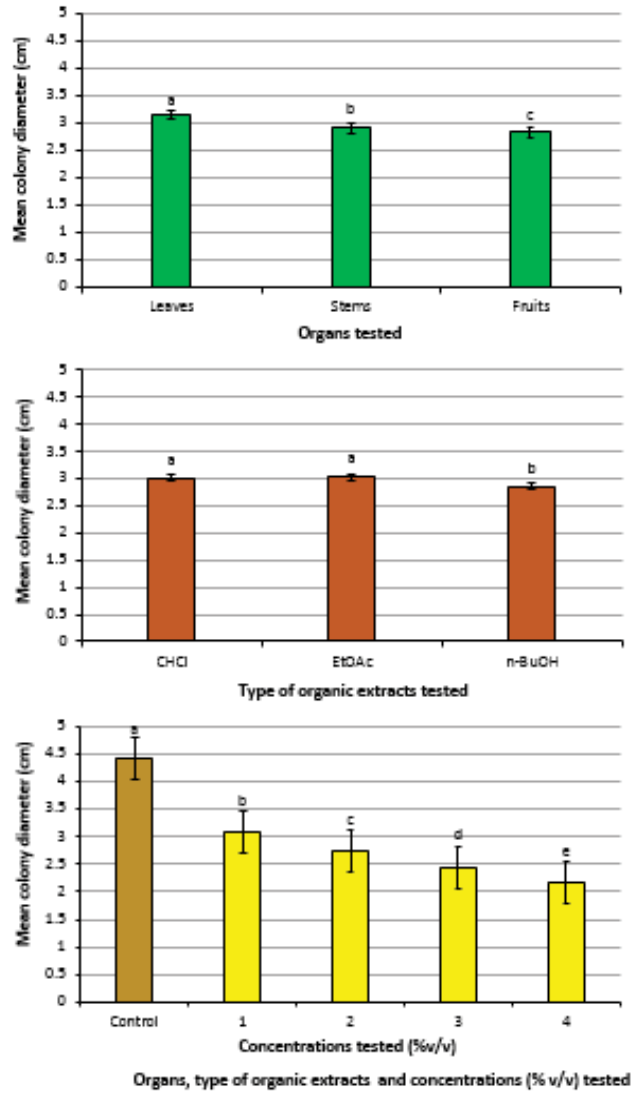

Figure 6: Mean colony diameter $(\mathrm{cm})$ of Fusarium oxysporum f. sp. radicislycopersici grown on PDA medium supplemented with different organic extracts from Withania somnifera depending on organs used, concentrations tested and organic solvents used for extraction noted after 5 days of incubation at $25^{\circ} \mathrm{C}$.

Negative control (untreated control): PDA+DMSO. Leaves; Stems; Fruits: Organs used from Withania somnifera. $\mathrm{CHCl}$ : Chloroform; EtOAc: Ethyl acetate; $\mathrm{n}-\mathrm{BuOH}$ : Butanol. 1; $;$; 3 and 4 (\% v/v): Concentrations used for each treatment. Bars show standard error. For each organ, for each type of organic extract used, and for each concentration tested, bars sharing the same letter are not significantly different according to Student-Newman-Keuls (SNK) test (at $P \leq 0.05$ )

yielded more dry residues than that of chloroform and ethyl acetate. In fact, butanol extractions' yields were $1.38,1.23$, and $1.53 \%$ for fractions from leaves, stems and fruits, respectively. It was also shown that butanol stems extracts induced the highest mycelial growth inhibition (62.03\%) compared to chloroform (51.89\%) and ethyl acetate $(48.48 \%)$ fractions. This antifungal potential may be due to the presence of some polar constituents such as glycoside, saponins, tannins, and flavonoides which could be present in butanolic fractions as shown in previous studies [34].

All W. somnifera aqueous extracts had significantly reduced FORL mycelial growth at all concentrations tested. Fruit extract was found to be the most active at $2 \%$ leading $56.28 \%$ lower growth relative to the untreated control. However, for the other organs, the highest antifungal potential was noted at $4 \%$ (40.08 and $43.20 \%$ achieved using leaf and stem extracts, respectively). Similarly, Shafique et al. [35] showed that W. somnifera aqueous extracts had significantly reduced by $49 \%$ the incidence of the black pointed disease of Triticum aestivum incited by $A$. alternata. This significant antifungal effect could probably be 
Citation: Nefzi A, Aydi Ben Abdallah R, Jabnoun-Khiareddine H, Medimagh-Saïdana S, Haouala R, et al. (2016) Antifungal activity of aqueous and organic extracts from Withania somnifera L. against Fusarium oxysporum f. sp. radicis-lycopersici. J Microb Biochem Technol 8: 144-150. doi: $10.4172 / 1948-5948.1000277$

attributed to some bioactive polar and water soluble metabolites. Indeed, phytochemical analysis of $W$. somnifera aqueous leaf and stem extracts revealed the presence of carbohydrates, glycosides, alkaloids, phytosterols, fixed oils, phenolic compounds, flavonoids, withaferin A, ascorbic acid, anthocyanin, and polyphenols which are known to have antifungal potential [34,36-38]. However, few data are available concerning use of wild Solanaceae metabolites for FCRR control in tomato. However, Shivpuri and Gupta [39] showed that leaf aqueous extracts from $W$. somnifera, Datura stramonium and Physalis longifolia are able to inhibit Sclerotinia sclerotiorum. On other hand, Onalar and Yilar [40] showed that flower aqueous extracts from Trachystemon orientalis L. have completely inhibited FORL mycelial growth when applied at the concentrations 5, 7, 10, and 20\%. In addition, Marley [41] showed that dry neem (Azadirachta indica) seed extract has totally suppressed $F$. oxysporum growth at all tested concentrations $(10,20$ and $30 \%)$.

Chloroform, ethyl acetate and butanolic extracts showed significant antifungal potential against FORL mycelial growth but with varied levels depending on types of organic extracts, plant material used for extraction, and concentrations tested. These results are in agreement with findings from previous studies. Indeed, Khrishnamoorthy et al. [42] demonstrated that antifungal activity is pathogen-specific and depends on solvent, crude extract concentration, temperature, and plant parts used for extraction of secondary metabolites. This could be attributed to their differences in chemical nature, polarity, and solubility of active biomolecules in each used solvent. Few studies have reported the antifungal activity of $W$. somnifera organic extracts (chloroform, ethyle acetate, and butanolic) against FORL. In fact, Khan and Nasreen [43] showed that $W$. somnifera methanolic extracts reduce the colony diameter of $F$. oxysporum by $71.11 \%$ as compared to the untreated control. It was also shown that $W$. somnifera protein fractions exhibit strong antifungal activity.

For chloroform extracts, those from stems and fruits were found to be more effective against FORL where fungus radial growth was reduced by more than $50 \%$ relative to $45 \%$ obtained using leaf extracts. Similarly, chloroform extract from $W$. somnifera calyx shows highest antibacterial activity toward B. subtilis [44]. Our results are also in accordance with those of Javaid and Munir [45] who showed that $W$. somnifera fruit and leaf methanolic extracts are highly effective against Ascochyta rabiei, the causal of chickpea blight disease, leading to 41 and $43 \%$ decrease in fungal biomass, respectively.

Ethyl acetate extracts from $W$. somnifera leaves, stems, and fruits had significantly inhibited the growth of the target fungus by more than $45 \%$. Ethyl acetate fruit extract had limited pathogen growth by $51.70 \%$ at the highest concentration tested (4\%). Similarly, Uddin et al. [46] demonstrated that ethyl acetate fraction from $W$. somnifera fruits was found to be active againt various bacterial agents such as Klebsiella pneumoniae, S. aureus, and B. subtilis. In this regard, Uddin et al. [46] reported that preliminary phytochemical screening of $W$. somnifera fruits revealed the presence of bioactive secondary metabolites such as alkaloids, saponins, glycosides, steroids, terpenoids, tannins, coumarins, and reducing sugars which are reported to have antimicrobial properties.

The present study pointed out that FORL was more sensitive to W. somnifera butanolic fractions compared to chloroform and ethyl acetate ones. The strongest inhibition, of about $62 \%$, occurred using stem butanolic extract applied at $4 \%$. Girish et al. [8] identified a monomeric glycoprotein from $W$. somnifera roots with potent activity against bacteria and phytopathogenic fungi. Some important chemical compounds are identified in $W$. somnifera including withaferin A, flavonol, glycosides, glycowithanoldes, phenolics, and sterols which could be involved in its antifungal activity.

Several works reported the antifungal effects of $W$. somnifera organic extracts against some phytopathogenic fungi. Indeed, Krishnamurthy et al. [47] showed that methanolic leaf powder of $W$. somnifera inhibited, by about $51 \%$, the growth of A. flavus in soybean seeds till six months of storage. Similarly, Jat and Agalave [48] found that Penicillium notatum and P. chrysogenum growth was hampered by the leaf extract of $W$. somnifera. In addition, Javaid and Akhtar [49] showed that methanolic extracts from $W$. somnifera roots decreased the fungal biomass of F. oxysporum f. sp. cepae by up to $93 \%$.

\section{Conclusion}

Current work is the first report on the in vitro antifungal activity of chloroform, ethyl acetate and butanol extracts from W. somnifera leaves, stems and fruits, against FORL. Results showed that W. somnifera extracts exhibited significant antifungal effect against this pathogen. Stem and fruit butanol extracts were found to be the most bioactive, mainly when used at the highest concentration (4\%). Bioactive compounds from $W$. somnifera extracts, involved in the registered antifingal activity, could serve as a potential source of natural derived fungicides once their efficacy proved in vivo on FORL-infected tomato plants. Moreover, purification and chemical identification of their bioactive compounds may elucidate more accurately the mechanisms of action involved in pathogen inhibition.

\section{Acknowledgments}

This work was funded by the Ministry of Higher Education and Scientific Research of Tunisia through the funding allocated to the research unit UR13AGR09-Integrated Horticultural Production in the Tunisian Centre-East, The Regional Centre or Research on Horticulture and Organic Agriculture, ChottMariem, Sousse, Tunisia.

\section{References}

1. McGovernn RJ (2015) Management of tomato diseases caused by Fusarium oxysporum. Crop Prot 73: 78-93.

2. Jarvis WR (1988) Fusarium crown and root rot of tomatoes. Phytoprotection 69: $49-64$

3. Hibar K, Daami-Remadi M, El Mahjoub M (2007) Induction of resistance in tomato plants against Fusarium oxysporum f. $\mathrm{sp}$. radicis-lycopersici by Trichoderma spp. Tunisian J Plant Prot 2: 47-58.

4. Ramaiah KA, Garampalli RKH (2015) In vitro antifungal activity of some plant extracts against Fusarium oxysporum f. sp. Iycopersici. Asian J Plant Sci Res 5: 22-27.

5. Hibar K, Daami-Remadi M, Hamada W, El-Mahjoub M (2006) Bio-fungicides as an alternative for tomato Fusarium crown and root rot control. Tunisian $J$ Plant Prot 1: 19-29.

6. Kerkeni A, Daami-Remadi M, Tarchoun N, Ben Khedher M (2007) In vitro and in vivo suppression of Fusarium oxysporum $\mathrm{f}$. sp. radicis-lycopersici the causal agent of Fusarium Crown and Root Rot of tomato by some compost fungi. Int J Agric Res 2: 1022-1029.

7. Kerkeni A, Daami-Remadi M, Tarchoun N, Ben Kheder M (2008) Effect of bacterial isolates obtained from animal manure compost extracts on the development of Fusarium oxysporum f. sp. radicis-lycopersici. Asian J Plant Pathol 2: 15-23.

8. Girish KS, Machiah KD, Ushanandini S, Harish Kumar K, Nagaraju S, et al. (2006) Antimicrobial properties of a non-toxic glycoprotein (WSG) from Withania somnifera (Ashwagandha). J Basic Microbiol 46: 365-374.

9. Hadian S, Rahnama K, Jamali J, Eskandari A (2011) Comparing neem extract with chemical control on Fusarium oxysporum and Meloidogyne incognita complex of tomato. AdvEnviron Biol 5: 2052-2057.

10. Javid A, Samad S (2012) Screening of allelopathic trees for their antifungal 
Citation: Nefzi A, Aydi Ben Abdallah R, Jabnoun-Khiareddine H, Medimagh-Saïdana S, Haouala R, et al. (2016) Antifungal activity of aqueous and organic extracts from Withania somnifera L. against Fusarium oxysporum f. sp. radicis-lycopersici. J Microb Biochem Technol 8: 144-150. doi: 10.4172/1948-5948.1000277

potential against Alternaria alternata strains isolated from dying-back Eucalyptus spp. Nat Prod Res 26: 1697-1702.

11. Pizana CG, Necha LLB, Gomez MYR (2010) Evaluation of the fungicidal activity of leaves powders and extracts of fifteen mexican plants agains Fusarium oxysporum f. sp. gadioli (Massey) snyder and hansen. J Plant Pathol 9: 103-111.

12. Ramezani H (2014) Antifungal activity of Eucalyptus spp. extracts against Alternaria solani on tomato. Int J Biolog Pharma Res 5: 790-793.

13. Aman M, Rai VR (2015) Antifungal activity of fungicides and plant extracts against yellow sigatoka disease causing Mycosphaerella musicola. Curr Res Environ Appl Mycol 5: 277-284.

14. Parekh J, Chanda S (2006) In vitro antimicrobial activity of some indian folklore medecinal plants. J Cell Tissue Res 6: 577-580.

15. Maya C, Thippanna M (2015) in vitro antifungal evaluation of various botanical extracts against early blight disease (Alternaria solani) of tomato. International Journal of Science and Nature 6: 264-267.

16. Haouala R, Hawala S, El-Ayeb A, Khanfir R, Boughanmi N (2008) Aqueous and organic extracts of Trigonella foenum-graecum L. inhibit the mycelia growth of fungi. J Environ Sci (China) 20: 1453-1457.

17. Mdee LK, Masoko P, Eloff JN (2009) The activity of extracts of seven common invasive plant species on fungal phytopathogens. South Afr J Bot 75: 375-379.

18. Al-Rahmah AN, Mostafa AA, Abdel-Megeed A, Yakout SM, Hussein SA (2013) Fungicidal activities of certain methanolic plant extracts against tomato phytopathogenic fungi. Afr J Microbiol Res 7: 517-524.

19. Cillo F, Pasciuto MM, De Giovanni C, Finetti-Sialer MM, Ricciardi L, et al. (2007) Response of tomato and its wild relatives in the genus Solanum to cucumber mosaic virus and satellite RNA combinations. J Gen Virol 88: 3166-3176.

20. Torabzadeh P, Panahi P (2011) Evaluation of antifungal activity of Physalis alkekengi L. extracts on Microsporum canis, Candida albicans, Trichophyton mentagrophytes and Nocardia asteroids. American-Eurasian J Agric \& Environ Sci 11: 863-866.

21. Indhumathi T, Mohandass S (2014) Efficacy of ethanolic extract of Solanum incanum fruit extract for its antimicrobial activity. Int J Curr Microbiol Appl Sci 3: 939-949.

22. Bari MA, Islam W, Khan AR, Abul Mandal (2010) Antibacterial and antifungal activity of Solanum torvum (Solanaceae). Int J Agric J 12: 386-390.

23. Sheeba E (2010) Antibacterial activity of Solanum Surattense burm. f. Kathmandu University Journal of Science, Engineering and Technology 6: 1-4.

24. Yogananth N, Buvaneswari S, Muthezhilan R (2012) Larvicidal and antibacteria activities of different solvent extracts of Solanum nigrum LINN. Global J Biotechnol Biochem 7: 86-89.

25. Inampudi S (2014) Antifungal activity of some wild plant extracts against fungal pathogens. Int J Intg Med Sci 1: 41-44.

26. Dhuley JN (1998) Therapeutic efficacy of Ashwagandha against experimental aspergillosis in mice. Immunopharmacol Immunotoxicol 20: 191-198.

27. Mahesh B, Satish S (2008) antimicrobial activity of some important medicinal plant against plant and human pathogens. World J Agric Sci 4: 839-843.

28. Kaur H, Goya RR, Bhattacharya A, Gupta R, Kumar Lal N, et al. (2015) Antifungal activity of phyto-extracts of Piper longum, Aloe vera, and Withania somnifera against human fungal opportunistic pathogen Candida albicans. DU Journal of Undergraduate Research and Innovation 1: 107-115.

29. Baka ZAM (2010) Antifungal activity of six Saudi medecinal plant extracts against five phytopathogenic fungi. ArchPhytopathol Plant Prot 43: 736-743.

30. Oryan A, Naeini AT, Nikahval B, Gorjian E (2010) Effect of aqueous extract of Aloe vera on experimental cutaneous wound healing in rat. Veterinarski arhiv 80: $509-522$.

31. Chaouche TM, Haddouchi F, Ksouri R, Atik-Bekkara F (2014) Evaluation of antioxidant activity of hydromethanolic extracts of some medicinal species from South Algeria. J Chin Med Assoc 77: 302-307.

32. Grover RK, Moore JD (1962) Toximetric studies of fungicides against brown rot organism Sclerotina fruticola. Phytopathology 52: 876-880.

33. Askarne L, Talibi I, Boubaker H, Boudyach EH, Msanda F, et al. (2012) In vitro and in vivo antifungal activity of several Moroccan plants against Penicillium italicum, the causal agent of citrus blue mold. Crop Prot 40: 53-58.

34. Santhi M, Swaminathan C (2011) Evaluation of antibacterial activity and phytochemeical analysis of leaves of Withania somnifera L. Dunal. Int J Curr Res 33: 10-12.

35. Shafique S, Bajwa R, Javaid A, Shafique R (2006) Antifungal activity of aqueous extracts of weeds against pathogen of black pointed disease of wheat seeds. Pak J Phytopathol 18: 174-177

36. Uddin Q, Samiulla L, Singh VK, Jamil SS (2012) Phytochemical and pharmacological profile of Withania somnifera Dunal: A review. J Appl Pharm Sci 2: $170-175$

37. Scalbert A (1991) Antimicrobial properties of tannins. Phytochemistry 30: 3875-3883.

38. Dharajiya D, Patel P, Patel M, Moitra N (2014) In vitro antimicrobial activity and qualitative phytochemical analysis of Withania somnifera L. Dunal extracts. In J Pharm Sci Rev Res 27: 349-354.

39. Shivpuri A, Gupta RBL (2001) Evaluation of different fungicides and plan extracts against Sclerotinia sclerotiorum causing stem rot of mustard. Indian Phytopathol 54: 272-274

40. Onaran A, Yilar M (2012) Antifungal activity of Trachystemon orientalis L. aqueous extracts against plant pathogens. J Food Agric Environ 10: 287-291.

41. Agbenin ON, Marley PS (2006) In vitro assay of some plant extracts against Fusarium oxysporum f. sp. lycopersici causal agent of tomato wilt. J Plant Prot Res 46: 117-121

42. Krishnamoorthy K, Subramaniam $P$, Senguttuvan J (2013) In vitro antifunga activity of various extracts of leaf and stem parts of Solena amplexicaulis Lam. Gandhi. Int J Pharm Sci 3: 745-747.

43. Khan ZS, Nasreen S (2010) Phytochemical analysis, antifungal activity and mode of action of methanol extracts from plants against pathogens. J Agric Technol 6: 793-805.

44. Singariya P, Mourya KK, Kumar P (2011) Antimicrobial Activity of the Crude Extracts of Withania somnifera and Cenchrus setigerus. Phcog J 4: 60-65.

45. Javaid A, Munir R (2012) Bioassay guided fractionation of Withania somnifera for the management of Ascochyta rabiei. Int J Agric Biol 14: 797-800.

46. Uddin G, Gul S, Rauf A (2013) Preliminary phytochemical screening, in vitro antimicrobial and antioxidant evaluation of Withania somnifera Dunal. World Appl Sci J 27: 562-565

47. Krishnamurthy YL, Shashikala J, Shankar Naik B (2008) Antifungal potential of some natural products against Aspergillus flavus in soybean seeds during storage. J Stored Prod Res 44: 305-309.

48. Jat JG, Agalave HR (2013) Fungitoxic properties of some leaf extracts against oilseed-borne fungi. Science Research Reporter 3: 210-215.

49. Javaid A, Akhtar R (2015) Antifungal activity of methanolic root extract of Withania somnifera against Fusarium oxysporum f. sp. cepae. Afr J Tradit Complement Altern Med 12: 22-27. 